\title{
The Effect of MySQL Workbench in Teaching Entity-Relationship Diagram (ERD) to Relational Schema Mapping
}

\author{
Li Yang \\ University of West Georgia/ Department of Computer Science, Carrollton, GA, USA \\ Email: lyang@westga.edu \\ Li Cao \\ University of West Georgia, Carrollton/Department of Educational Technology and Foundations, GA, USA \\ Email: 1cao@westga.edu
}

\begin{abstract}
While designing a database at the conceptual level using the Entity-Relationship (ER) model is challenging for novices, mapping an Entity-Relationship Diagram (ERD) to a relational schema is not an easy task, either. One of the problems is students' lack of understanding of the underlying mapping principles. The mental gap between the two models in students also makes it difficult for them to perform the conversion. This paper describes two studies that aimed at helping students fill the gap and improve their ERD-Relational schema mapping performance by the use of a visualization tool, MySQL Workbench. We investigated the effect of using MySQL Workbench in teaching ERDRelational schema mapping. We identified the pros and cons of using visualization in teaching the topic. Our results show that visualization can increase student interest and engagement, and facilitate students connecting the concepts in the two models. With an instructional delivery method that emphasizes the underlying mapping principles, a visualization tool could help undergraduate students improve their performance on ERD-relational schema mapping and facilitate their understanding of the ER model.
\end{abstract}

Index Terms - Entity-relationship model, relational model, relational schema, entity-relationship diagram, visualization, ERD-relational schema mapping.

\section{INTRODUCTION}

Data modeling is an important component of the curriculum of both Computer Science [1] and Information Systems programs [20]. According to the Computer Science Curricula 2013 report, “...student needs to be able to develop conceptual and physical data models". To develop a conceptual data model, it typically involves analyzing the problem domain and coming up with a database diagram using the EntityRelationship (ER) model [9]. The diagram is then converted into a relational schema before the physical database is created and implemented. While it is challenging for novices to learn to design a database at the conceptual level due to the abstract and complex nature of data modeling [10,12,17, 19, 24], it is not an easy task mapping an ERD (Entity-Relational Diagram) to a relational schema. Even though it may seem straightforward to experienced database designers mapping an ERD to a relational schema, our over ten years' student performance record on database design shows that our CS students have not performed well on this topic. Their average grade on ERD-Relational schema mapping homework over an 11-year period is 71.70 (out of 100) which is only 1.70 points higher than their average grade on ER modeling homework.

Our observation of this challenge is also confirmed by recent research studies. As described in [10] and [12], "the skills to map a conceptual model to a logical/design are "hard" technical skills", and they are "different from ...knowing the components of an ER model....". To overcome these challenges, it is important for students to learn the concepts and skills, and to develop a holistic view of conceptual design and ERD-relational schema mapping. Student understanding and skills in these areas may impact the quality of their final database design. One cannot expect a good logical model from students who do not fully understand the principles behind the conversion process, even if they could come up with a good conceptual model. However, little research is found in investigating how to improve student performance in ERD-relational schema mapping

One of the problems we encountered frequently when teaching ERD-Relational schema mapping is students' lack of understanding of the underlying mapping principles. Many students often mechanically follow the rules to perform the mapping without a clear understanding why they should map things a certain way. While memorizing or mechanically following the mapping rules may result in the temporary correct result, this kind of rote learning does not promote deep learning and understanding [24]. As a result, students often end up with incorrect relational schema after the initial class instruction. This is mostly because either they misuse a rule or completely forget to apply some rules. This 
problem reveals a disconnection between applying the rules and understanding the effects of the rules among students.

This paper reports our research that aimed at helping students establish the connection between the conceptual model and logical model via the use of visualization. We posit that visualization may help in closing the mental gap students have on the two models and assist students to achieve a better understanding of the mapping principles, which in turn may improve their mastery of database design at the conceptual level. The visualization tool we chose is MySQL Workbench [25], which is a free client program with many features to facilitate database design. One such feature is to create an Enhanced-ER Diagram (EERD). Users can drag and drop icons representing tables and connect them using 1:1 (identifying or non-identifying), or 1:M (identifying or non-identifying), or M:N (identifying) relationships. This feature automatically creates an intersection table and adds the foreign key into it for $\mathrm{M}: \mathrm{N}$ relationships. For 1:1 and 1:M relationships, it adds the foreign key to the table that user clicks first. The end result is essentially a relational schema, though named EERD.

We conducted two studies over a two-year period. The first study examined whether a visualization-based instructional approach, compared with a more traditional lecture-based instructional approach, could improve student performance on ERD-Relational schema mapping. As a follow-up study, the second study examined whether an enhanced visualization-based instructional method would improve student understanding of 1:1 and M:N relationship mapping.

The rest of the paper is organized as follows. Section 2 presents the background information. Section 3 describes the research questions, methodologies, procedures, results and discussions of the two studies. A general discussion is presented in Section 4. The conclusions and future work are presented in Section 5.

\section{BACKGROUND}

Though the concepts of the ER model are simple, conceptual database design using the ER model is often a difficult and complex task for novices. Researchers have investigated the underlying obstacles to the problem $[1,4$, $5,10,12,17,18,19,24]$. The obstacles include students' poor understanding and conception of the problem domains, and abstract and complex relationships among entities etc.

To overcome the obstacles, researchers have investigated varied visualization tool-based support for learning ER modeling [12, 16, 17, 21, 22, 24]. Visualization, playing an important role in learning and instruction, has been used in teaching programming and algorithms [6, 7, 8] and other topics in Computer Science. Research shows that if properly applied with active student engagement, visualization helps students develop a correct mental model of the concepts in instructional settings [7, 26, 28]. Furthermore, an interactive visualization with feedback on correctness further helps students engage in active learning instead of passive receiving $[7,16]$.

For instance, Hall and Gordon [16] described a textbased Virtual Learning Environment (VLE) where users interacted with objects in a virtual world and were given immediate feedback on their design. The preliminary results indicated a tool such as VLE might help increase novice designers' understanding of ER modeling. Similarly, Kolp and Zimanyi [21] developed an environment in which users' design was checked and explanation was provided at the time of errors. However, the study focused more on the development of the method rather than on the effectiveness of the environment for student learning. Moreover, Murray and Guimaraes [24] presented a set of animations as supplementary instructional materials to teach database analysis and design. They followed the typical database design process and included animations for ER modeling ER-Relational schema mapping, normalization, and denormalization. However, neither qualitative nor quantitative results were reported in the study.

Alternatively, several researchers applied problembased learning [3] or project-based learning in teaching database design and analysis [10, 12, 22, 23]. Both problem-based learning and project-based learning are based on the constructivist theory of learning which was attributed to Jean Piaget [27]. Constructivist theory advocates that learners internalize knowledge by constructing it through active engagement in the process. It emphasizes student-centered learning and teachers acting as facilitators to guide rather than teach students during the learning process. The main difference between problem-based and project-based learning is the former is focused on inquiry and research, and the problem given is typically well-articulated; while the latter is focused on the end project and may involve any number of problems [10]. Connolly, Stansfield, and McLellan [12] applied the problem-based learning approach in their study. They investigated using an educational simulation game to supplement traditional teaching methods to increase student engagement and performance. Their preliminary result on a partially implemented visual learning environment showed the online group that was given access to the game, even though limited in its features, performed significantly better than the other groups in terms of grades. Kreie and Ernst [22] also applied problem-based learning in teaching database analysis and design. They used several Oracle products in hands-on tutorials and problem-solving assignments to facilitate student learning. However, no qualitative or quantitative results were reported.

On the other hand, Connolly \& Begg [10] described a project-based learning approach to teaching database analysis and design. Their preliminary qualitative and quantitative results showed that the constructivist approach improved student learning. However, "the results were not fully conclusive because the effect could have been entirely attributable to online delivery rather than the project-based approach" [10, pp. 50]. 
As these studies show, different approaches have been explored [10, 11, 12, 22, 23], to facilitate student learning of database analysis and design. Database analysis and design process as a whole encompasses user requirement gathering and analysis, data modeling at the conceptual level using ER or Unified Modeling Language (UML), logical database design by mapping a conceptual model (ERD or UML class diagram) to a relational schema, and normalization. Compared to these studies, the present study focused only on ERD-relational schema mapping, which is an integral step in database analysis and design. Our study attempted to address the challenges that students face in their initial mapping of an ERD to a relational schema as novices. In particularly, our studies addressed the lack of understanding of the ER model and confusion in connecting the ER model and relational model that students encountered in developing a complete and accurate relational schema. Similar to other colleagues [12, 22, 23], we explored visualization in facilitating student learning. In particular, we used a problem-based learning as our instructional approach for in-class exercises and a project-based learning for a term project in which students were asked to design and implement a database-driven application. To examine the effects of visualization, we collected quantitative and qualitative data. Admittedly, it has become a common practice to use commercial visualization products in teaching database design including ERD-Relational schema mapping. However, to the best of our knowledge, there has not been similar empirical studies that examined effects of using visualization tools with quantitative and qualitative results in the literature. It is our hope that the current research would shed some light on the effects of visualization in ERD-Relational schema mapping.

\section{EVALUATION OF THE EFFECT OF MYSQL WORKBENCH IN TEACHING ERD-RELATIONAL SCHEMA MAPPING}

In order to examine the effect of MySQL Workbench in ERD-Relational schema mapping, we carried out two studies.

Study A focused on comparing the use of MySQL Workbench in teaching the topic with a more traditional lecture-based instructional approach. The study examined the effect of the visualization-based approach in different instructional settings (face-to-face vs. online), and in different student groups (undergraduate vs. graduate students). It also identified the strengths and weaknesses of the visualization-based instructional approach.

After identifying some ineffective aspects of the visualization approach in Study A, we revised the instructional delivery of the visualization approach. Study B investigated whether the revised visualizationbased approach helped improving student performance for undergraduate students in a face-to-face class and graduate students in an online class.

\section{A. Study A: An Evaluation Of Visualization In Teaching} ERD-Relational Schema Mapping

\section{Research questions}

In Study A, we specifically addressed the following research questions:

I. Does the use of a visualization tool (i.e., MySQL Workbench) improve student performance of ERD-Relational Schema mapping?

II. Does the timing of when to introduce a visualization tool in the class have an impact on student performance of the mapping?

III. What are the pros and cons of using a visualization tool in teaching the ERD-Relational Schema mapping principles?

\section{Research methodology}

This study was conducted at a regional public university in the Southeast of US in fall of 2013. There were two sections of a Computer Science (CS) undergraduate face-to-face database course, CS3230 Information Management (IM), and one section of an online CS graduate database course, CS6231 Database Systems I (DB I).

The undergraduate IM course is a traditional database course, which covers the relational data model, conceptual database design using the ER model, ERDRelational schema mapping, SQL, normalization, transaction processing, and programmatic database access. In each class meeting, after the normal instruction time, the students were given hands-on exercises (e.g., designing an ERD for a database, writing SQL queries, etc.) to practice and explore what they had just learned in class, and to construct the knowledge on their own. The students were encouraged to ask their fellow classmates or the instructor for clarification and to search the internet for additional resources. The instructor acted as a coach to facilitate their learning by making clarifications on the problems, providing hints, and offering feedback. In addition to the in-class problem-based learning activities, the students were engaged in project-based learning. They were given a semester-long group project to design and implement a database-driven application based on instructor-designed requirements. They were asked to integrate what they had learned in Software Engineering I (the prerequisite of CS3230) and the present course to design and implement the front-end and back-end of the application. The project ran in parallel with class instructions. After the topics on ER modeling, and ERD-Relational schema mapping were covered in class, the students were asked to start to design and implement the database for the project. The project-based learning aimed to create an environment in which the students could apply and integrate what they have learned in class into a small-scale project.

Our graduate program is an Applied M.S. program. This unconventional program includes students who do not usually have a Bachelor's degree in Computer Science. Because of this feature, the coverage of the 
graduate course CS6231 (DB I) is very similar to CS3230 (IM). The only main difference is some topics, such as transaction processing and programmatic database access, are not covered in CS6231. Another difference is the graduate students are not given a term project because they need more preparation on software development. All these missing components are offered in the subsequent course, CS6232 Database Systems II. Though the graduate course is on-line, the instructor provides tutorials, videos, and practice exercises in addition to homework and projects to facilitate their learning.

In both courses, ERD-Relational schema mapping was covered after ER modeling. The students in all the sections had never performed ERD-relational schema mapping previously. The total number of students in each section was 18, 19, and 13, respectively. After eliminating the students who did not participate in all the assessments, there were 11,12 , and 12 students respectively who agreed to participate in the study.

For clarity, the demographics and nature of the teaching environment of these groups are shown below:

- $\quad$ G1 $(n=11)$ : undergraduate students in a face-toface class

- $\quad \mathrm{G} 2(n=12)$ : undergraduate students in a face-toface class

- $\quad \mathrm{G} 3(n=12)$ : graduate students in an online class

\section{Research procedure}

As our teaching experience showed, the major bottleneck for students to learn the ERD-relational schema mapping is in the area of mapping binary relationships $(1: 1,1: \mathrm{m}$, and $\mathrm{m}: \mathrm{m}$ relationships) and identifying referential integrity constraints. Enlightened by this information, our instruction focused on analyzing the correctness of students' work in those areas. Note that our lessons included additional concepts, such as weak entities, multi-valued attributes, and n-nary relationships which are also difficult for students to understand in ER modeling. We did not, however, focus on how to map those constructs. This is because we used a variation of the crow's foot notation [14] for ERDs. In that notation, multi-valued attributes and n-nary relationships are represented as weak entities. Weak entities in the ERD are mapped to tables in the relational schema. Therefore, we did not consider those constructs here. The study consisted of the following steps:

1) Students in all the sections were given a pre-test before they were introduced to the topic. In the pretest, they were asked to convert an ERD into a relational schema. They had learned about the ER model and relational data model, and thus had a basic understanding of both models. The pre-test served as the baseline measure for the study.

2) After the pre-test, students were engaged in the lesson topic. To evaluate the effect of using a visualization tool, we adopted three different instructional approaches for the three sections.
Based on the specific instructional approaches, these sections were grouped into two categories as follows:

- Category \#1 (Lecture-based format):

- Approach \#1: For the face-to-face undergraduate section 1 (G1), the mapping principles were presented in a regular lecture format in which the instructor explained the mapping rules with examples for each case.

$\circ$ Approach \#2: For the online graduate section G3, students were given a video of the lecture in which the instructor showed the PowerPoint lecture slides and explained the mapping rules with examples for each case, and demonstrated how to perform mapping on a sample problem.

- Category \#2 (Visualization-based Demonstration):

- Approach \#3: For the face-to-face undergraduate section 2 (G2), the instructor demonstrated how to use MySQL Workbench to perform ERDRelational schema mapping in class with explanations.

3) After the mapping rules were explained, the students in all the sections were given in-class exercises on ERD-Relational schema mapping. For the students in the undergraduate section (G1) and the graduate section (G3), they were asked to write out the mapping results based on the lecture slides. For the undergraduate section (G2), the students were asked to perform the mapping using MySQL Workbench, and then write out the results. The reasons for writing out the result is to make sure the students understand more abstract representation of the logical model and can make the transition from a graphical interface to it. From our experience, many students often take little attention on specifying the primary keys, foreign keys, and which tables are the referenced tables. Graphical representations of tables and relationships may inadvertently mask those fundamental and critical components of a relational schema. Writing out the schema requires students to reflect on their mapping, thus provides a better picture of their understanding of the mapping. We used these written results to examine how the tool impacted student comprehension of the mapping rules. In the in-class exercises, there were one 1:1 relationship, three 1:M relationships (and we used the average grade to report the 1:M case), and one M:N relationship.

4) Then in the next class session, in order to further test the effect of the tool and to give all the students the benefit of different instructional approaches, we reversed the instructional approaches for the sections as follows.

- For the undergraduate section (G1), students were presented with the tool and showed how to use the tool to perform the mapping. 
- For the undergraduate section $(\mathrm{G} 2)$, students were presented with the mapping principles in a lecture format.

- For the graduate section $(\mathrm{G} 3)$, the students were given a PDF tutorial that showed how to use the MySQL Workbench to perform the mapping.

5) After that, the post-test was given. The post-test problem was identical to the pre-test problem. Because no answers were given to the students after the pre-test, and the mapping problem was not simple, we felt the likelihood is slim that the students may perform better on the post-test due to the same problem being given at pre- and post-test. In addition, even if some students used rote memorization when performing mapping, we expect that the impact on the final mapping result would be similar in all the sections. We believe visualization is to motivate students to achieve a better understanding of the mapping and not to eliminate rote learning. There were two 1:1 relationships (and we picked the one that was similar to the one in the in-class exercise to report the result for the 1:1 case), two 1:M relationships (and we used the average grade for the 1:M case because both 1:M relationships are very similar to the ones in the in-class exercise), and one $M: N$ relationship. The post-test measure asked the students to use MySQL Workbench to perform the mapping, then to write out their solutions on paper.

6) Along with the post-test, we also gave a post-survey, which asked the students how they felt about the tool and if the tool helped or impeded their understanding of ERD-Relational schema mapping.

On all the assessments (pre-test, in-class exercises, and post-test), we assigned grades based on the correctness of the mapping of each component (e.g. 1:1, 1:M, M:N, specifying referential integrity) and used them in the quantitative analysis. The total points awarded for each mapping task are shown in Table 1 and Table 4.

\section{Findings}

To address Research Question \#1 (Does the use of a visualization tool improve student performance of ERDRelational Schema mapping?), we compared student performance on the in-class exercise and the pre-test. The in-class exercises were given after all the groups were initially presented the material using different instructional approaches. The differences among the groups would indicate which approach was more effective for student learning. The descriptive statistics of mapping $1: 1, \quad 1: \mathrm{M}$, and $\mathrm{M}: \mathrm{N}$ relationships, all relationships $(1: 1,1: \mathrm{M}, \mathrm{M}: \mathrm{N})$, specifying referential integrity constraints and the grand total in the pre-test, inclass exercises, post-test for all three groups are presented in Table 1.

Table 1. Descriptive Statistics of the Performance of G1, G2, and G3 in Mapping 1:1, 1:M, M:N Relationships, Specifying Referential Integrity Constraints, All Relationships (1:1, 1:M, M:N Relationships Mapping) and the Grand Total in the Pre-test, In-class Exercise, and Post-test.

\begin{tabular}{|c|c|c|c|c|c|c|c|c|c|}
\hline & \multicolumn{3}{|c|}{$\begin{array}{c}\text { G1 }(\mathrm{n}=11) \\
\text { (Lecture-based+ visualization) }\end{array}$} & \multicolumn{3}{|c|}{$\begin{array}{c}\text { G2 }(n=12) \\
\text { (Visualization-based + Lecture })\end{array}$} & \multicolumn{3}{|c|}{$\begin{array}{l}\qquad \text { G3 }(\mathrm{n}=12) \\
\text { (Lecture Slides \&Video + } \\
\text { visualization PDF) }\end{array}$} \\
\hline & Pre & In-class & Post & Pre & In-class & Post & Pre & In-class & Post \\
\hline $\begin{array}{l}\text { Mapping } \\
\text { tasks }\end{array}$ & $\begin{array}{c}M \\
(S D)\end{array}$ & $\begin{array}{c}M \\
(S D) \\
\end{array}$ & $\begin{array}{c}M \\
(S D) \\
\end{array}$ & $\begin{array}{c}M \\
(S D) \\
\end{array}$ & $\begin{array}{c}M \\
(S D) \\
\end{array}$ & $\begin{array}{c}M \\
(S D) \\
\end{array}$ & $\begin{array}{c}M \\
(S D) \\
\end{array}$ & $\begin{array}{c}M \\
(S D) \\
\end{array}$ & $\begin{array}{c}M \\
(S D) \\
\end{array}$ \\
\hline $\begin{array}{l}1: 1 \\
\text { relationship } \\
\left(\mathbf{R}_{1: 1}, 3 p t s\right)\end{array}$ & $\begin{array}{l}1.09 \\
(1.51)\end{array}$ & $\begin{array}{c}0.27 \\
(0.90)\end{array}$ & $\begin{array}{l}1.64 \\
(1.57)\end{array}$ & $\begin{array}{c}0.96 \\
(1.42)\end{array}$ & $\begin{array}{c}1.50 \\
(1.57)\end{array}$ & $\begin{array}{c}2.00 \\
(1.48)\end{array}$ & $\begin{array}{l}2.25 \\
(1.36)\end{array}$ & $\begin{array}{c}2.04 \\
(1.29)\end{array}$ & $\begin{array}{l}2.75 \\
(0.87)\end{array}$ \\
\hline $\begin{array}{l}1: M \\
\text { relationship } \\
\left(\mathbf{R}_{1: M}, \mathbf{3 p t s}\right)\end{array}$ & $\begin{array}{c}0.73 \\
(0.93)\end{array}$ & $\begin{array}{c}1.32 \\
(1.32)\end{array}$ & $\begin{array}{c}1.73 \\
(1.44)\end{array}$ & $\begin{array}{c}1.13 \\
(1.28)\end{array}$ & $\begin{array}{l}2.85 \\
(0.31)\end{array}$ & $\begin{array}{c}2.81 \\
(0.44)\end{array}$ & $\begin{array}{c}1.38 \\
(1.33)\end{array}$ & $\begin{array}{c}2.78 \\
(0.46)\end{array}$ & $\begin{array}{c}2.63 \\
(0.93)\end{array}$ \\
\hline $\begin{array}{l}\mathrm{M}: \mathrm{N} \\
\text { relationship } \\
\left(\mathbf{R}_{\mathrm{M}: \mathrm{N}}, 3 \text { pts }\right)\end{array}$ & $\begin{array}{c}1.68 \\
(1.19)\end{array}$ & $\begin{array}{c}2.09 \\
(1.36)\end{array}$ & $\begin{array}{c}2.27 \\
(1.27)\end{array}$ & $\begin{array}{c}1.21 \\
(1.50)\end{array}$ & $\begin{array}{c}2.79 \\
(0.26)\end{array}$ & $\begin{array}{c}2.58 \\
(1.00)\end{array}$ & $\begin{array}{c}2.42 \\
(0.97)\end{array}$ & $\begin{array}{c}2.71 \\
(0.86)\end{array}$ & $\begin{array}{c}2.96 \\
(1.44)\end{array}$ \\
\hline $\begin{array}{l}\text { Specifying } \\
\text { referential } \\
\text { integrity } \\
\text { constraints } \\
\text { (rf, 13pts) }\end{array}$ & $\begin{array}{c}5.09 \\
(3.14)\end{array}$ & $\begin{array}{c}5.64 \\
(4.08)\end{array}$ & $\begin{array}{c}8.37 \\
(3.85)\end{array}$ & $\begin{array}{c}6.58 \\
(4.93)\end{array}$ & $\begin{array}{c}9.33 \\
(2.99)\end{array}$ & $\begin{array}{l}11.00 \\
(2.22)\end{array}$ & $\begin{array}{l}6.42 \\
4.66)\end{array}$ & $\begin{array}{l}10.83 \\
(2.98)\end{array}$ & $\begin{array}{l}10.75 \\
(2.38)\end{array}$ \\
\hline $\begin{array}{l}\text { Total of all } \\
\text { relationships } \\
\left(\mathbf{R}_{1: 1}+\mathbf{R}_{1: m}+\right. \\
\mathbf{R}_{\text {m:n }} \\
\mathbf{9} \text { pts })\end{array}$ & $\begin{array}{c}3.50 \\
(2.35)\end{array}$ & $\begin{array}{c}3.68 \\
(2.45)\end{array}$ & $\begin{array}{c}5.64 \\
(3.45)\end{array}$ & $\begin{array}{c}3.29 \\
(3.26)\end{array}$ & $\begin{array}{c}7.14 \\
(1.82)\end{array}$ & $\begin{array}{c}7.40 \\
(2.61)\end{array}$ & $\begin{array}{c}6.04 \\
(2.73)\end{array}$ & $\begin{array}{c}7.53 \\
(1.96)\end{array}$ & $\begin{array}{c}8.33 \\
(1.17)\end{array}$ \\
\hline $\begin{array}{l}\text { Grand Total } \\
\left(\mathbf{R}_{1: 1}+\mathbf{R}_{1: \mathrm{m}}+\right. \\
\mathbf{R}_{\mathrm{m:n}}+\mathbf{r f ,} \mathbf{2 2} \\
\text { pts) }\end{array}$ & $\begin{array}{c}8.59 \\
(5.29)\end{array}$ & $\begin{array}{c}9.31 \\
(6.05)\end{array}$ & $\begin{array}{l}14.00 \\
(7.17)\end{array}$ & $\begin{array}{c}9.88 \\
(8.04)\end{array}$ & $\begin{array}{l}16.47 \\
(4.38)\end{array}$ & $\begin{array}{l}18.40 \\
(4.50)\end{array}$ & $\begin{array}{l}12.46 \\
(6.57)\end{array}$ & $\begin{array}{l}18.36 \\
(4.84)\end{array}$ & $\begin{array}{c}19.08 \\
(3.29)\end{array}$ \\
\hline
\end{tabular}


As Table 1 shows, Group 2 (G2) which was applied with the visualization-based approach made the biggest improvement in all the cases, except for specifying referential integrity constraints, in which case Group 3 (G3) made the biggest improvement. These results suggest that the use of MySQL Workbench through demonstration prior to lecture improved student performance of ERD-Relational Schema mapping compared to the traditional lecture-based instructional approach.

To answer Research Question \#2 (if the ordering of the instructions matters), we compared the post-test and pretest results of all three groups. The reason is all the groups were presented the topic in both lecture presentation as well as visualization demonstration by the post-test time. The only difference is when the visualization tool was introduced. The results in Table 1 indicate that on the post-test:

- the students in the group that was introduced the visualization tool earlier (G2) consistently performed better on all the cases than the group that was introduced the tool later $(\mathrm{G} 1)$. This result indicates that introducing the tool earlier would enhance undergraduate student performance on ERD-Relational schema mapping.

- the graduate class (G3) which was introduced the tool later performed better than $\mathrm{G} 2$ on $1: 1, \mathrm{M}: \mathrm{N}$ relationships mapping, total relationships mapping, and the grand total in terms of mean grades. However, the group (G2) achieved the highest gains in all the cases, when the post-test results were compared to the pretest results.

Table 2. One-way ANOVA and Bonferroni Post Hoc Test of Performance of G1, G2, and G3 on Pre-test, In-class Exercise, and Post-test with $p<$ 0.05 .

\begin{tabular}{|c|c|c|c|c|}
\hline Mapping Tasks & Mean Difference & $\mathrm{F}$ & $P$ & $\mathrm{y}^{2}$ \\
\hline In-class $\left(1: 1\right.$ relationship, $\left.\mathrm{R}_{1: 1}\right)$ & $\mathrm{M}_{\mathrm{G} 3}-\mathrm{M}_{\mathrm{G} 1}=1.77$ & 10.76 & 0.003 & 0.26 \\
\hline In-class (1:M relationship, $\left.\mathrm{R}_{1: \mathrm{M}}\right)$ & $\begin{array}{l}\mathrm{M}_{\mathrm{G} 2}-\mathrm{M}_{\mathrm{G} 1}=1.53 \\
\mathrm{M}_{\mathrm{G} 3}-\mathrm{M}_{\mathrm{G} 1}=1.46\end{array}$ & 18.87 & $\begin{array}{l}0.000 \\
0.000\end{array}$ & 0.45 \\
\hline In-class (specifying referential integrity constraints) & $\begin{array}{l}\mathrm{M}_{\mathrm{G} 2}-\mathrm{M}_{\mathrm{G} 1}=3.67 \\
\mathrm{M}_{\mathrm{G} 3}-\mathrm{M}_{\mathrm{G} 1}=5.20\end{array}$ & 13.67 & $\begin{array}{l}0.039 \\
0.002\end{array}$ & 0.31 \\
\hline $\begin{array}{l}\text { In-class (grand total = total relationships }+ \text { specifying referential integrity } \\
\text { constraints) }\end{array}$ & $\begin{array}{l}\mathrm{M}_{\mathrm{G} 2}-\mathrm{M}_{\mathrm{G} 1}=7.15 \\
\mathrm{M}_{\mathrm{G} 3}-\mathrm{M}_{\mathrm{G} 1}=9.04\end{array}$ & 17.98 & $\begin{array}{l}0.006 \\
0.001\end{array}$ & 0.38 \\
\hline Post-test (1: M relationships, $\left.\mathrm{R}_{1: \mathrm{M}}\right)$ & $\mathrm{M}_{\mathrm{G} 2}-\mathrm{M}_{\mathrm{G} 1}=1.09$ & 6.38 & 0.044 & 0.19 \\
\hline
\end{tabular}

Next, we conducted the One-Way Analysis of Variance (ANOVA) to find out if there was statistically significant performance difference among all three groups. Table 2 reports the ANOVA result for $\mathrm{p}<0.05$. As Table 2 shows, there is a significant difference among the three groups on all in-class tasks except $M: N$ relationship mapping, and on the post-test 1:M relationship mapping. Furthermore, to find out which groups performed significantly higher on the tasks evaluated, we conducted Bonferroni post hoc test (see Table 2).

In order to verify the quantitative data, we also collected qualitative data via an open-ended question in the post-survey. The post-survey question is "please explain honestly how you feel about using the tool for ERD-Relational mapping (do you feel it helps you understand the mapping or it actually hinders your understanding). And if it helps you, please tell me in what way. If it confuses you, please also tell me in what way". The results are reported in Table 3.

Table 3. Student Responses to the Survey Question (if the Tool Helped Them Understand the Mapping).

\begin{tabular}{|l|l|l|l|}
\hline & Positive & Neutral & Negative \\
\hline $\begin{array}{l}\text { G1 undergraduate } \\
(\boldsymbol{n}=\mathbf{1 1})\end{array}$ & $72.72 \%(8)$ & $18.18 \%(2)$ & $9.09 \%(1)$ \\
\hline $\begin{array}{l}\text { G2 undergraduate } \\
(\boldsymbol{n}=\mathbf{1 2})\end{array}$ & $91.66 \%(11)$ & $0(0)$ & $8.33 \%(1)$ \\
\hline $\begin{array}{l}\text { G3 Graduate } \\
(\boldsymbol{n}=\mathbf{1 2})\end{array}$ & $75 \%(9)$ & $25 \%(3)$ & $0(0)$ \\
\hline Total $(\boldsymbol{n = 3 5 )}$ & $80 \%(28)$ & $14.29 \%(5)$ & $5.71 \%(2)$ \\
\hline
\end{tabular}

As Table 3 shows, students in three groups all reported positively to the helpfulness of the visualization tool in understanding the mapping. Their perceived endorsement ranged from $72.72 \%$ for the undergraduate students in $\mathrm{G} 1$, to $91.66 \%$ for the undergraduate students in $\mathrm{G} 2$, and to $75 \%$ for the graduate students in G3.

In addition to their rating, students commented that the visual representation of tables and relationships in the tool made it easier for them to understand the mapping process, and seeing the database design in tables also helped them understand the ERD.

\section{Discussion}

The evidence of significant performance improvement of G2 over G1 on 1:M relationship mapping suggests that visualization did help improving student performance on 1:M relationship mapping. A possible explanation is once students created a 1:M relationship, the tool automatically added a foreign key in the table on the M-side, thus resulted in the correct mapping. Another possible explanation is automatic creation of a foreign key provided explicit feedback to students, thus it helped students internalize the correlation between 1:M relationships in ERDs and foreign keys in relational schemas. Finally, early exposure of G2 to the tool may also attribute to G2's better performance.

Therefore, it is unclear if the improvement on 1:M mapping is attributable to visualization alone, or automation of the tool in mapping 1:M relationships, or early exposure to the tool. Nevertheless, we felt the value of visualization should not be underestimated. Our data support the previous research findings that interactive 
visualization with feedback on the correctness of the answers would increase student understanding [7, 16]. The use of DBMS tools may carry students from a lower level of Bloom's taxonomy (e.g., comprehension) to a higher one (e.g., application or synthesis) [23]. Preliminary results in [24] also supported the value of visualization (more specifically, animations) in students' learning of database design including ERD-Relational schema mapping.

Analysis of the qualitative data of student perceptions also supports the positive effect of visualization on student learning:

"... The tool does help visualize it. It also helps on deciding where to put foreign keys. ..."

"The tool definitely helped understand how certain relationships worked out."

"I think that using the MySQL tool to map ER diagrams into relational models simplifies the process. It's easier for me to understand when I can see the relationships between the two. Since the MySQL tool automatically creates foreign keys when a relationship is added, it was much easier for me to learn how to map ERDs to relational models."

As for 1:1 and $\mathrm{M}: \mathrm{N}$ relationships mapping, the visualization tool did not seem to have a strong impact on student performance on the in-class exercise and post-test For 1:1 relationships, it could be due to the following reason. A 1:1 relationship in an ERD is typically mapped as a foreign key in the relational schema. When using the visualization tool to map a 1:1 relationship, one has to determine which table to click first in order for the tool to add the foreign key in that table. Essentially, students have to understand the underlying mapping principle for this case in order to map it correctly. The tool does not provide explicit feedback on the correctness of this case. We posited failure to understand the mapping rule for this case is the key factor that prevents students from mapping it correctly. In order to address this issue and to leverage the power of visualization on student understanding, we need to carefully design the visualization-based instructional delivery approach by emphasizing the underlying mapping principle of the case so that students can map 1:1 relationships correctly.

For M:N relationships, the non-significant performance difference between the groups can be explained by the fact that the mapping principle for $\mathrm{M}: \mathrm{N}$ is pretty straightforward. All one needs to do is to create a new table. The students seemed to understand it so that no significant performance difference incurred among the three groups in the in-class exercise and post-test.

The significant performance differences between G2 and G1, and G3 and G1 in the in-class exercise on specifying integrity constraints were not retained in the post-test. This might be explained by the fact that the visualization tool only establishes the foreign key relationships between tables, however, the tool does not explicitly show the directions of the references. But interestingly, why G2 and G3 performed better in the inclass exercise? Bergin et al. [7] reported that good visualization encourages students to explore and thus promotes active learning. Deeper learning occurs when students are engaged in exploring and constructing the knowledge [10, 12, 15, 23]. Our data support these observations. We speculate that during the in-class exercises, the students in G2 might have taken the time to explore the tool to explicitly view the relationships to confirm their understanding, as they were learning to use the tool. The students in G3 could refer to the video. Furthermore, since the class for G3 was online, the students in G3 did not have a time limit on the exercises. All these factors might have contributed to the better performance of G2 and G3 in the in-class exercises. For the post-test, all students were given plenty of time, and they could all refer back to the lecture notes and use the tool to verify the results. Therefore, it did not show a significant difference among all three groups.

The statistically significant performance difference on the in-class exercises between the two groups G1 and G3 was a little surprising. Both groups were categorized under the same Category \#1 (Lecture-based format). The difference between the groups is the class for G1 was a face-to-face undergraduate class, while G2 was an online graduate class and the students were given lecture slides and a video to watch. We speculate that two factors might have caused the performance difference. First, the graduate students were older, more mature, and more motivated than the undergraduate students. Second, the graduate students in G3 were given a video that explained the mapping principles and demonstrated how to perform mapping with an example. Previous research [7, 26] has found that one of the best practices of applying visualization is to "complement visualizations with explanations". Murray and Guimaraes [24] also provided feedback in their animations to reinforce classroom instruction. The study in [12] provided ways for students to drill down to basic concepts to enhance learning. Students in G3 could view the video as many times as they want. All of these factors might have helped G3 students understand the principles better than G1 which was only presented with a lecture in class once.

We also noticed that the introduction of the visualization tool seemed to have complicated the mapping process for some students (about 6\% overall), as the students had to learn to use the tool before performing the mapping. Possible learning curve sometimes causes instructors and students to avoid using visualization tools [7]. However, unlike complex graphical CASE tools which impose understandable learning challenges for beginners [18], the tool we used, MySQL Workbench, is relatively simple. We posit that this problem could be alleviated by instructors spending more time explaining and demonstrating the visualization tool, and providing more assistance during class exercise time.

B. Study B: an Evaluation of the Enhanced Visualization-based Approach in ERD-Relational Schema Mapping

Study A showed that MySQL Workbench helped the undergraduate students on mapping 1:M relationships, but not much on 1:1 and M:N relationships. As discussed 
above, the reason for less improvement on student performance on M:N relationship mapping might be due to the ceiling effect that the underlying mapping principle for it is straightforward and easy to understand. Because of the simplicity of the rule, students were able to perform the mapping correctly even without the help of the tool. For 1:1 relationships, it was obvious that the students did not really understand the mapping rule, as the visualization tool did not provide immediate feedback on the correctness of the mapping. Therefore, the key here is to improve students' comprehension of the underlying principles for 1:1 relationships. Many studies $[7,10,12,22,26]$ suggested that instruction plays an important role in making visualization effective. If we could adjust the teaching delivery approach to help students understand the underlying principle better, it could improve their performance. Furthermore, since we only had one graduate class in Study A that used the traditional lecture-based approach, we wanted to set up an intervention group so that we could examine the treatment effect. Therefore, we conducted Study B as a follow-up study to address these two issues.

\section{Research questions}

Study B aimed to answer the following questions:

1) Does an enhanced visualization-based approach help undergraduate students perform better on 1:1 as well as on M:N relationship mapping? In particular, we were interested in examining the effectiveness of 1:1 relationship mapping using the enhanced approach.

2) Does an enhanced visualization-based approach help the graduate students perform better on ERDRelationship schema mapping, as compared to the traditional lecture-based approach?

\section{Research methodology}

As a follow-up study, Study B was conducted in fall of 2014, one year after Study A. Study B included one section of a CS undergraduate face-to-face CS3230 (IM), and one section of an online CS graduate CS6231 (DB I). The total number of students in each section was 18 and 31, respectively. After eliminating the students who did not participate in all the assessments, there were 12 and 29 students respectively who agreed to participate in the study. The demographics and nature of the teaching environment of these groups are shown below:

- G4 $(n=12)$ : undergraduate students in a face-toface class

- G5 ( $n=29)$ : graduate students in an online class

\section{Research procedure}

The study followed a similar procedure to that of Study A. The students in both sections were given a pre-test before being introduced to the topic. After the pre-test, the students in G4 were shown how to perform mapping using MySQL Workbench. This time, the instructor adjusted the delivery method by spending extra time explaining the rationale behind mapping 1:1 and M:N relationships. With the help of the tool, the instructor demonstrated two different ways to map 1:1 relationships and asked the students to identify which way was wrong and which was correct and why. This enhanced scaffolding instruction approach was to help the students develop their abilities to make sense of the mapping result when using the tool so that they could formulate the correct mental model. The students in G5 watched a video created by the instructor. The video demonstrated how to perform mapping using the tool. Then, the students in both sections were given in-class exercises in which they were asked to perform ERD-Relational schema mapping. After that, the students in G4 were presented with the mapping principles in a lecture format, and the students in G5 were asked to review the lecture slides. Again, the post-test and the post-survey were given afterward. The post-test problem was identical to the pre-test problem, except that it also asked the students to explain why they mapped certain relationships the way they did. The post-survey was identical to the one in Study A.

\section{Findings}

To address the first research question of Study B, we first compared the performance of G1 (from Study A) and G4 (from Study B). Both groups consisted of undergraduate students. For G1, lecture-based lessons followed by a visualization tool demonstration was applied, while for G4, an enhanced visualization-based approach followed by a lecture was applied. We wanted to see if G4 would perform better on mapping especially on 1:1 relationships mapping. Table 4 reports the descriptive statistics of mapping 1:1, 1:M, and $\mathrm{M}: \mathrm{N}$ relationships, all relationships $(1: 1, \quad 1: \mathrm{M}, \mathrm{M}: \mathrm{N})$, specifying referential integrity constraints and the grand total in the pre-test, in-class exercises, post-test for the G1 and G4.

As Table 4 shows, the group G4 scored higher than the group G1 in terms of mean grades on the in-class exercise and post-test in all the cases.

An independent-samples t-test (Table 5) was conducted to compare performance difference in G1 and G4 on the pre-test, in-class exercises, and post-test.

These results suggest that the enhanced visualizationbased approach improved student performance right after the intervention because students in G4 (the enhanced instructional approach) performed statistically significantly higher on all the cases than students in the control group G1 on the in-class exercises. The improvement may be attributed to either the tool, or the extra time spent, or early exposure to the tool. In study A, there was no visible significant performance improvement between G1 and G2. Therefore, we posit that the improvement may result from the improved instructional method. Furthermore, on 1:1 relationships mapping as well as on the combined total relationship mapping on the post-test, students in G4 performed significantly higher, on average, than students in G1. The results suggest that when the enhanced visualization 
Table 4. Descriptive Statistics of the Performance of G1 and G4 in Mapping 1:1, 1:M, M:N Relationships, Specifying Referential Integrity Constraints, All Relationships (1:1, 1:M, M:N Relationships Mapping) and the Grand Total in the Pre-test, in-class Exercise, and Post-test.

\begin{tabular}{|c|c|c|c|c|c|c|}
\hline \multirow[t]{3}{*}{ Mapping Tasks } & \multicolumn{3}{|c|}{$\begin{array}{c}\text { G1 (n=11) } \\
\text { (Lecture-based + visualization) }\end{array}$} & \multicolumn{3}{|c|}{$\begin{array}{c}\text { G4 }(\mathrm{n}=12) \\
\text { (Enhanced visualization + lecture) }\end{array}$} \\
\hline & Pre & In-class & Post & Pre & In-class & Post \\
\hline & $M(S D)$ & $M(S D)$ & $M(S D)$ & $M(S D)$ & $M(S D)$ & $M(S D)$ \\
\hline 1:1 relationship $\left(R_{1: 1}, 3 p t s\right)$ & $1.09(1.51)$ & $0.27(0.90)$ & $1.64(1.57)$ & $1.25(1.54)$ & $2.25(1.36)$ & $3.00(0.00)$ \\
\hline 1:M relationship ( $\left.\mathbf{R}_{1: \mathrm{M}}, 3 \mathrm{pts}\right)$ & $0.73(0.93)$ & $1.32(1.32)$ & $1.73(1.44)$ & $0.67(1.01)$ & $2.67(0.49)$ & $2.50(0.88)$ \\
\hline M:N relationship ( $\left.\mathbf{R}_{\mathrm{M}: \mathrm{N}}, 3 \mathrm{pts}\right)$ & $1.68(1.19)$ & $2.09(1.36)$ & $2.27(1.27)$ & $1.25(1.29)$ & $2.96(0.14)$ & $2.92(0.19)$ \\
\hline $\begin{array}{lll}\begin{array}{l}\text { Specifying } \\
\text { constraints } \\
\text { (rf, 13pts) }\end{array} & \text { referential } & \text { integrity } \\
& & \\
\end{array}$ & $5.09(3.14)$ & $5.64(4.08)$ & $8.37(3.85)$ & $4.67(3.39)$ & $10.50(2.20)$ & $9.75(3.05)$ \\
\hline $\begin{array}{l}\text { Total of all relationships }\left(\mathbf{R}_{1: 1}+\mathbf{R}_{1: \mathrm{m}+}\right. \\
\left.\mathbf{R}_{\mathrm{m}: \mathrm{n}}, \mathbf{9} \mathrm{pts}\right)\end{array}$ & $3.50(2.35)$ & $3.68(2.45)$ & $5.64(3.45)$ & $3.17(2.80)$ & $7.88(1.42)$ & $8.42(0.87)$ \\
\hline $\begin{array}{l}\text { Grand Total }\left(\mathbf{R}_{1: 1}+\mathbf{R}_{1: \mathrm{m}}+\mathbf{R}_{\mathrm{m:n}+} \mathbf{r f}, 22\right. \\
\text { pts })\end{array}$ & $8.59(5.29)$ & $9.31(6.05)$ & $14.00(7.17)$ & $7.83(5.97)$ & $18.34(3.38)$ & $18.17(3.52)$ \\
\hline
\end{tabular}

Table 5. Independent-samples t-test of the Performance of G1 and G4 in Mapping 1:1, 1:M, M:N Relationships, Specifying Referential Integrity Constraints, All Relationships (1:1, 1:M, M:N Relationships Mapping) and the Grand Total in the Pre-test, In-class Exercise, and Post-test.

\begin{tabular}{|c|c|c|c|c|c|}
\hline Mapping tasks & $\begin{array}{c}\text { G1 } \\
\text { M(SD) }\end{array}$ & $\begin{array}{c}\text { G4 } \\
\text { M(SD) }\end{array}$ & $\mathbf{t}(21)$ & $p$ & $\eta^{2}$ \\
\hline In-class (1:1 relationship, $\left.\mathbf{R}_{1: 1}\right)$ & $0.27(0.90)$ & $2.25(1.36)$ & 4.07 & 0.001 & 0.44 \\
\hline In-class (1:M relationship, $\left.\mathbf{R}_{1: \mathrm{M}}\right)$ & $1.32(1.32)$ & $2.67(0.49)$ & 3.31 & 0.003 & 0.34 \\
\hline In-class (M:N relationship, $\mathbf{R}_{\mathrm{M}: \mathrm{N}}$ ) & $2.09(1.36)$ & $2.96(0.14)$ & 2.21 & 0.039 & 0.20 \\
\hline In-class (total relationships $=\mathbf{R}_{1: 1}+\mathbf{R}_{1: \mathrm{M}}+\mathbf{R}_{\mathrm{M}: \mathrm{N}}$ ) & $3.68(2.45)$ & $7.88(1.42)$ & 5.09 & 0.000 & 0.55 \\
\hline In-class (specifying referential integrity constraints) & $5.63(4.08)$ & $10.5(2.20)$ & 3.60 & 0.002 & 0.38 \\
\hline In-class (grand total = total relationships + specifying & $9.31(6.05)$ & $18.38(3.38)$ & 4.48 & 0.000 & 0.49 \\
\hline Post-test(1:1 relationship, $\left.\mathbf{R}_{1: 1}\right)$ & $1.64(1.57)$ & $3(0.00)$ & 3.02 & 0.006 & 0.30 \\
\hline Post-test (total relationships) & $5.64(3.45)$ & $8.48(0.79)$ & 2.78 & 0.011 & 0.27 \\
\hline
\end{tabular}

approach was applied, students were able to continue performing well on 1:1 relationship mapping.

To address the second research question of Study B, we also conducted an independent-samples t-test of mapping performance between the two graduate classes, G3 (in Study A) and G5 (in Study B). However, no significant difference was found between the two groups.

In the post-test, we asked the students why they mapped certain relationships the way they did. Their written responses showed the majority of the students understood the mapping principles. However, some of the answers were off track and did not indicate appropriate reasoning to their mapping results. We intend to follow up with one-on-one interviews to better understand their perception of the underlying mapping principles and reasoning in their mapping process.

The post-survey results are presented in Table 6. As can be seen, students in G4 and G5 reported overwhelmingly $(>85 \%)$ that the tool helped them understand ERD-Relational schema mapping.

In both studies, the students commented on the helpfulness of the visualization tool on facilitating their understanding of ERD-Relational schema mapping as well as understanding of the connection between ERD and relational schema. We have categorized their comments below based on the themes.

Table 6. Student Responses to the Question (if the Tool Helped Them Understand the Mapping).

\begin{tabular}{lllll}
\hline G4 undergraduate $(\boldsymbol{n}=\mathbf{1 2})$ & $\begin{array}{l}\text { Positive } \\
100 \%(12)\end{array}$ & $\begin{array}{l}\text { Neutral } \\
0(0)\end{array}$ & $\begin{array}{l}\text { Negative } \\
0 \%(0)\end{array}$ \\
G5 Graduate & $(\boldsymbol{n}=\mathbf{2 9})$ & $86 \%(25)$ & $7 \%(2)$ & $7 \%(2)$ \\
\multicolumn{1}{l}{ Total } & $(\boldsymbol{n}=\mathbf{4 1})$ & $90 \%(37)$ & $5 \%(2)$ & $5 \%(2)$ \\
\hline
\end{tabular}

Theme 1: Visualization facilitates student understanding of the mappings.

- "I felt the tool really helped me understand the mappings. It gives a visual representation of the table structure/relations."

- "I like the tool it does help me a lot. It helps me understand the mapping process because it breaks it down and makes it more simplistic."

Theme 2: Visualization helps to expose design flaws. 
- "I think the tool allows users to see relationships that they might not have realized exist previously. The diagram also shows users where flaws might be in their design, due to the automated cardinalities assigned to relationships.”

Theme 3: Visualization helps students see the connection between the concepts in the ER model and the ones in the relational model.

- 'I like workbench. I think it's a great tool and it makes it easy to understand the differences between a relational schema and an ER. It shows how the tables will actually be implemented. A great tool."

- "I enjoy using workbench because I believe it gives a better understanding of how the database is supposed to connect and work together."

- "I think that the tool in MySQL is helpful. It bridged the ideas I knew into one, and therefore concreted my understanding."

- "I really like the mysql EER interface.... I like workbench's ability to switch between actual tables and model view because if I am concerned whether or not the model is correct, I can create it correctly as tables and then convert it to a model and see if they match. This removes a lot of the guess and checks from Diagram generation whereas crow's feet in visio had a steep learning curve for me."

Theme 4: Visualization helps students understand ERDs.

- "The workbench tool is quite successful. I feel like it helped me understand ER diagrams, I still have trouble fully understanding them but I do believe that it helps me understand it by showing me in another way."

- "The tool is good and I think it gives me a better understanding of ER Diagrams. They were confusing to me until I was actually able to look at the tables and see how they work. The tool was very helpful in helping me understand ER Diagrams."

\section{Discussion}

In Study B, we found G4 performed significantly higher than G1 on all the cases of the in-class exercises, indicating the enhanced visualization-based approached helped the undergraduate students immediately after the approach was applied. The improvement on 1:1 relationship mapping was also retained as shown by the post-test result. These findings are very encouraging and inspiring for improving our instruction on 1:1 relationship mapping. We intend to carry out follow-up studies to sort out whether the improvement is due to either the tool, or the extra time spent, or early exposure to the tool.

Our data show that the approach did not yield a significant performance difference on $\mathrm{M}: \mathrm{N}$ relationship mapping. This confirms our speculation that the M:N case is easy to understand even without the help of the tool. Nevertheless, the enhanced instructional approach did improve the combined relationships mapping performance. This result indicates although the enhanced approach did not lead to a statistically significantly improvement on mapping 1:M and $\mathrm{M}: \mathrm{N}$ relationships individually, the combined effect was significant. Therefore, this approach is still worth applying in a faceto-face undergraduate class setting.

We were a little surprised by the non-significant difference between the two graduate classes. This finding suggests that providing a demo video that explained the mapping did not seem to help much. We speculated again this might be due to the graduate students being more mature and more motivated. The original PDF tutorial seemed to work just as fine.

Students' responses to the open-ended survey questions reveal that the use of the visualization tool made ERD-Relational schema mapping more interesting to them. Students were more engaged and willing to explore the connection between the ERDs and relational schemas. These findings are consistent with the previous research that visualization helps to get students' attention [7, 10, 12, 13, 24]. In addition, the students' feedback also indicated that the visualization tool facilitated their understanding of the ER model and its connection to the relational model.

\section{GENERAL DISCUSSION}

Study A showed that the group G2 (visualization-based + lecture approach) performed significantly better than the control group G1 throughout the assessment (on the in-class exercises and post-test) on 1:M relationships mapping. However, such improvement on 1:M relationships mapping was surprisingly not observable in Study B. In Study B, the students in G4 (enhanced visualization-based +lecture approach) performed significantly better than G1 on all the mapping tasks on the in-class exercises, but only the significance on 1:1 relationships mapping persisted to the post-test.

Both studies show that the effect of visualization in improving student performance is obvious right after the interventions, which indicates the effectiveness of the visualization tool. However, the outcomes only persisted to the post-tests in limited cases (i.e., 1:M relationships in Study A and 1:1 relationships in Study B). One possibility for these results is the students in all the groups have learned to use the visualization tool by the time of post-test, thus, the benefit of visualization and early exposure to the tool has disappeared except in the case of 1:1 or 1:M relationships mapping.

We are perplexed by the result that the improvement on 1:M relationships mapping is not retained to the posttest in Study B. The persistent improvement on 1:1 relationships mapping in Study B suggests that extra time spent in explaining the rationale behind the mapping pays off. Since such improvement was not observable in Study 
A and the difference between G2 and G4 is mainly on the extra time spent on explaining the mapping rationale, we see the potential of the enhanced visualization instructional approach.

\section{CONCLUSIONS AND FUTURE WORK}

Through Study A and Study B, we investigated the effect of a visualization tool (MySQL Workbench) in helping students learn ERD-Relational schema mapping. Our data allowed us to come to the following observations:

1) A visualization tool like MySQL Workbench makes learning more fun and students are more engaged.

2) Visualization may improve student performance in mapping 1:M relationships, however, what factors attribute to the improvement is not conclusive because the performance gain may be due to visualization alone, or automation of the mapping by the tool, or early exposure to the tool.

3) Visualization and early exposure to visualization does not seem to affect student performance significantly on M:N relationships mapping.

4) When visualization is introduced early and ample time is spent on the underlying principles, it improves student performance on 1:1 relationships mapping.

5) The effect of visualization is not obvious on improving our graduate student performance on ERD-Relational schema mapping.

6) The introduction of a new tool did seem to complicate the mapping process for some students, as the students had to learn to use the tool before performing the mapping.

While we are excited about the results, we recognize the limitations of the studies. First, our studies included relatively small sample sizes. Due to their small sample sizes, our results might not apply to a larger population. In addition, due to the design issue of the studies, we could not definitively attribute student performance improvement on 1:1 relationships mapping to early exposure to the visualization tool, or the enhanced instructional approach. However, based on students' feedback, and our classroom observations, and analyses of student performance, we believe MySQL Workbench functions well as a visualization tool. It not only helps students achieve a better understanding of ERDRelational schema mapping and of the ER model, but also helps them establish the connections between the abstract concepts of the ER model, such as entities, weak entities, and relationships, and the more concrete concepts of the relational model, such as tables and foreign keys.

For implications to teaching, we recommend integrating a tool like MySQL Workbench in teaching ERD-Relational schema mapping as early as possible. This approach would help prevent confusions that students often have about ER modeling. Furthermore, we recommend providing ample time to enable students to feel comfortable with the tool in class and spending more time explaining the rationale behind the mapping principles. After all, understanding the principles is the key to correct mapping. Visualization is just an approach to assisting students during the process. As for the online class setting, we recommend inclusion of videos that explain the principles as well as how to use the visualization tool.

In addition to a refined research design with a larger sample, we intend to include one-on-one interviews to investigate the level of student understanding. We believe that more in-depth qualitative data will help us determine more effective ways to help students master correct mapping through the automation of the tool and understanding of the principles. We would also like to see if the effect of visualization on ERD-relational schema mapping has any positive impact on database analysis and design in general. We believe that with a careful design and a larger sample size of different student groups, this research will advance our quest for a more effective instructional approach to conceptual and logical modeling.

\section{ACKNOWLEDGMENT}

We are grateful to Dr. Cher Hendricks for her feedback on the initial report of Study A. We also wish to thank all the students who participated in the studies.

\section{FUNDING}

This work was supported in part by University of West Georgia Institutional STEM Excellence (UWise) Grant funded by University System of Georgia STEM II Initiative.

\section{REFERENCES}

[1] Computer Science Curricula 2013 report, http://ai.stanford.edu/users/sahami/CS2013/final-draft/ CS2013-final-report.pdf, retrieved March 28, 2016.

[2] Ahrens, J., \& Song, I., EER data modeling aids for novice database designers. Proceedings of the $2^{\text {nd }}$ Int. Conf Information Resources Association, 99-114, 1991.

[3] Barrows, H. S. (1996). Problem-based learning in medicine and beyond: A brief overview. New Directions for Teaching and Learning, 1996(68): 3-12, doi:10.1002/tl.37219966804.

[4] Batra, D., \& Antony, S. R. (1994). Novice errors in conceptual database design. European Journal of Information Systems, 3(1), 57-69.

[5] Batra, D., \& Davis, J. (1992). Conceptual data modeling in database design: similarities and differences between expert and novice designers. International Journal of ManMachine Studies, 37, 83-101.

[6] Ben-Ari, M., Bednarik, R., Levy, R.B., Ebel, G., Moreno, A., Myller, N., \& Sutinen, E. (2011). A decade of research and development on program animation: The Jeliot experience. Journal of Visual Languages and Computing, 22, 375-384.

[7] Bergin, J., Brodie, K., Patino-Martinez, M., McNally, M., Naps, T., Rodger, S ... Jimenez-Peris, R. (1996). An 
overview of visualization: Its use and design: Report of the working group in visualization. Proceedings of the 1st Conference on Integrating Technology into Computer Science Education, 192-200.

[8] Cetin, I. (2013). Visualization: a tool for enhancing students' concept images of basic object-oriented concepts. Computer Science Education, 23(1), 1-23.

[9] Chen, P. P. (1976). The entity-relationship model - toward a unified view of data. ACM Trans. Database Systems, 1(1), 9-36.

[10] Connolly, T., \& Begg, M (2006). A constructivist-based approach to teaching database analysis and design, Journal of Information Systems Education, 17(1), 43-53.

[11] Connolly, T. M., MacArthur, E., Stansfield, M.H., \& McLellan, E. (2007). A Quasi-experimental study of three online learning courses in computing. Journal of Computers and Education, 49(2), 345-359.

[12] Connolly, T., Stansfield, M., \& McLellan, E (2006) Using an online games-based learning approach to teach database design concepts. The Electronic Journal of $e$ Learning, ,4(1), 103-110.

[13] Doman M., Sleigh, M., \& Garrison, C., (2015). Effect of GameMaker on student attitudes and perceptions of instructions, International Journal on Modern Education and Computer Science, 7(9), 1-13.

[14] Finkelstein, C. (1998). Information engineering methodology. In P. Bernus, K. Mertins \& G. Schmidt (Eds.), Handbook on architectures of information systems (pp. 405-427). Berlin, Germany: Springer-Verlag.

[15] Gance, S. (2002). Are constructivism and computer-based learning environments incompatible? Journal of the Association for History and Computing, 1, May, 2002.

[16] Hall, L., \& Gordon, A. (1998). A virtual learning environment for entity relationship modeling. SIGCSE 98, 345-349.

[17] Hoffer, J. (1982). An empirical investigation into individual differences in database model. Proceedings of 3rd Int. Conf. Information Systems, 153-167.

[18] Hoggarth, G.R., \& Lockyer, M.A. (1996). Systems development methods guidance and CASE: integration between CASE and CAL. Software Engineering Journal, 11(3), 141-147.

[19] Holmboe, C. (2005). Conceptualization and labelling as cognitive challenges for students of data modelling. Computer Science Education, 15(2), 143-161.

[20] IS-2010, IS 2010 Curriculum Guidelines for Undergraduate Degree Programs in Information Systems, http://www.acm.org/education/curricula/IS\%202010\%20A CM\%20final.pdf, retrieved March 28, 2016.

[21] Kolp, M., \&Zimanyi, E. (2000). Enhanced ER to relational mapping and interrelational normalization. Information and Software Technology, 42, 1057-1073.

[22] Kreie, J., \& Ernst, B. (2013). From database concepts to application: Use problem-based learning and Oracle development tools to facilitate learning. Proceedings of the Information Systems Education Conference, 2013.

[23] Mohtashami \& Scher, 2000, Application of Bloom's Cognitive Domain Taxonomy to Database Design, Proceedings of Information Systems Education Conference, 2000.

[24] Murray, M., \& Guimaraes, M. (2009) Animated Courseware Support for Teaching Database Design, Issues in Informing Science and Information Technology, 6, 201211.

[25] MySQL Workbench 6.3. Available from https://www.mysql.com/products/workbench/, retrieved March 28, 2016.
[26] Naps, T.L., Rößling, G., Almstrum, V., Dann, W., Fleischer, R., Hundhausen, C., ... \& Velázquez-Iturbide, J.Á. (2002). Exploring the role of visualization and engagement in computer science education. Proceedings of ITiCSE-WGR '02: Working group reports from ITiCSE on Innovation and technology in Computer Science Education, 131-152.

[27] Piaget, J. (1968), Six Psychological Studies, Vintage Books, New York.

[28] Sajaniemi, J., Byckling, P., \& Gerdt, P. (2007). Animation metaphors for object-oriented concepts. Electronic Notes in Theoretical Computer Science, 178, 15-22.

\section{Authors' Profiles}

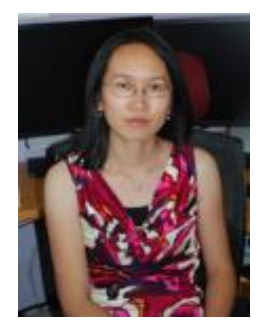

Li Yang, Ph.D. Dr. Yang is an Associate Professor in the Department of Computer Science at the University of West Georgia. She received her doctorate from Florida International University. She has taught a variety of undergraduate courses, such as Information Management, Computing Capstone, Parallel and Distributed Systems, CS1, CS2, Operating Systems, Web Technologies, among others, and graduate courses Operating Systems, and Database Systems I and II. Her research interests include Computer Science Education, Computer Security, and Database Systems.

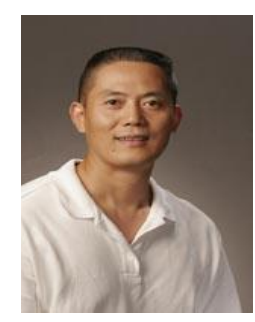

Li Cao, Ph.D. Dr. Cao is a Professor of Educational Psychology in the College of Education at the University of West Georgia. He received his doctorate from McGill University. $\mathrm{He}$ teaches undergraduate and graduate courses of Educational Psychology, Research Methods, \& Program Evaluation for teacher education and UTeach programs. His research focuses on metacognition and self-regulated learning in the traditional face-to-face and e-learning environment. His recent publications include a book on teacher reflection, book chapters on the mixed-method research, and educational technology applications in classroom, and journal articles on teacher game-based learning design, study strategy, help-seeking, student motivation, and self-efficacy. Prior to his appointment at UWG, Dr. Cao taught as an assistant professor at St. Mary's University in Minneapolis, Minnesota, a part-time instructor at McGill University, Canada, and a lecturer of English as Second Language in Chongqing University China. 